\title{
7I-Model for Smart Urban Management
}

\author{
Konstantin Semyachkov ${ }^{1,2}{ }^{*}$ Evgeny Popov ${ }^{2}$
}

\author{
${ }^{1}$ Institute of Economics, The Ural Branch of Russian Academy of Sciences, Yekaterinburg, Moskovskaya 29, Russia \\ ${ }^{2}$ Ural Institute of Management of the Russian Presidential Academy of National Economy and Public Administration, \\ Yekaterinburg, 8 Marta 66, Russia \\ *Corresponding author. Email: k.semyachkov@mail.ru
}

\begin{abstract}
The article presents the author's model of the stages of the formation of a smart city (model "7I"), it is shown that the following levels are the basis for the development of smart cities: engineering infrastructure, institutes, communication and communication systems, data integration, user and technical systems interaction, innovation, innovation in the components of a smart city. It has been determined that these levels of formation of smart cities are based on the use of advanced digital technologies and their applications: big data processing, the use of cloud technologies, digital platforms, blockchain technology, as well as procedures for shared economy, crowdsourcing, the Internet of things, etc. It is concluded that the formation of smart cities meets the national interests of states in the development of a digital society and ensures life safety in the context of the application of digital technologies.
\end{abstract}

Keywords: smart city, 7I-model, digital technologies, assessment, socio-economic development

\section{INTRODUCTION}

In the past few decades, the trend of urban development through the introduction of digital technology has become one of the dominant ideas in the formation of modern urban space. Advanced technologies, especially modern digital innovations, are increasingly seen as a tool to overcome the prevailing socio-ecological-economic contradictions [1]. Recently, the idea of the need to introduce digital technologies into the processes of urban environment management, digitalization of urban space, and the use of digital technologies in solving energy, environmental, and transport problems is developing more and more actively. Such a set of ideas in the scientific literature is defined as the concept of "smart city". Significant progress achieved through the development of digital technologies allows us to create a holistic design of the city of the future, which is increasingly based on smart technology and is increasingly associated with the implementation of the concept of smart development [2]. Although the concept of "smart city" is the result of research in the field of digital technologies, this concept is increasingly being studied in other areas of scientific research, including economics, ecology, sociology, which indicates the need to consider this phenomenon from a socio-economic point of view. This approach allows us to assess the prospects of the current urban environment on which the cities of the future will be built [3].

The concept of a smart city is widely used as a strategic tool to cover modern factors of urban production in a general framework and to increase the competitiveness of cities. Cities such as London and Barcelona marked the beginning of the development of the smart city model, expecting that it will lead to the effective management of cities, which is a requirement of any modern city. Analyzing research on the introduction of the concept of a smart city in the practice of managing modern cities, it can be noted that such a concept has found application in the leading cities of the world, increasing their effectiveness and competitiveness [4]. At the same time, despite a significant number of studies on smart cities, many issues of their formation and development remain unexplored. In particular, the main directions of the development of smart cities have not been identified, and priority directions have not been identified in the framework of the development of the urban environment in the context of digitalization. Therefore, the purpose of this study is to form the staged development of a smart city.

More and more often, a smart city is seen as an environment of open innovation driven by residents, where the city itself is a platform for interaction between interested parties, involving citizens in solving public issues. Openness is achieved through the development of various forms of relations between people, infrastructure and technology. Openness towards people facilitates the coordination of joint activities based on citizen engagement. Modern business models are focused on open products and services in the sense that consumers can participate in their development, thereby influencing the activities of companies. Open standards and technologies contribute to the involvement of the state, business, individual citizens in their development. Thus, open innovation systems contribute to effective social interaction.

Recently, ideas about the role of technology in social change, the convergence of the technological and social factors and the formation of sociotechnical innovations on this basis have been heard more and more often. Modern smart cities are a prime example of such innovations in modern conditions and are increasingly viewed from the point of view of the socio-technical processes taking place 
within them. One of the main problems in this case is the institutionalization and coordination of various stakeholders who participate and interact in these socio-technical processes. In this regard, within the framework of individual cities, strategies for the development of smart cities are increasingly being created that contribute to solving the problems of institutionalization and coordination [5].

The Internet of Things (IoT) plays an important role in the development of a smart city through monitoring, data collection, analysis and personalized service delivery methods. The Internet of things is already improving the quality of many services, including transport, housing and communal services, management, education and healthcare [6]. Other digitalization tools for the urban environment are cloud technologies, digital platforms, a sharing economy toolkit, as well as business models and forms of organizing economic activities based on crowdsourcing, crowdfunding, and other elements of a digital society.

In the conditions of the formation of a smart space of the urban environment, the priorities of urban development become interrelated and require the creation of a common information space and data management system to provide intellectual services to urban entities. In such circumstances, one of the main approaches to managing increasing flows of information resources is the concept of big data, which is a powerful tool for smart city applications. Current trends in the development of digital systems show how difficult it is to collect, manage, store and analyze big data. However, the large volume and variety of big data provides an excellent opportunity for creating intelligent applications that respond effectively to current data and offer accurate decision-making tools. Thanks to this technology, many countries of the world, such as South Korea, the USA and the UAE, are striving to create and support smart cities [7].

Researchers from India G. Yadav and colleagues [8] identified 33 main factors (enablers) that create the conditions for the formation of smart cities. They include factors of a purely economic nature (creating conditions for the development of entrepreneurship by optimizing taxation, attracting foreign direct investment, developing public-private partnerships, stimulating the influx of skilled labor, etc.), social (improving the quality of education and healthcare, developing the attractiveness of the territory for tourists, life safety, etc.), and environmental nature (for example, waste management). In essence, such factors can be regarded as investment tricks or measures to form smart cities.

The research group of G. Camboim and colleagues [9] came to the conclusion about the determining role of the level of control processes in the process of forming smart cities. Based on the analysis of published sources and the application of the case study method to study the practices of the cities of Barcelona, Amsterdam and Vienna (universally recognized flagships of "smartness"), scientists identified four main areas for implementing smart initiatives (social institutions, ecology, economics, management). In their opinion, socio-economic transformations can only be achieved if the processes are effectively managed at the city administration level. Using practical examples, it is proved that smart cities develop on the initiative "from above", through the implementation of the developed strategy and individual projects.

The role of institutions in the formation of smart cities is the subject of an article by P. Kummitha and N. Krutzen [10]. Using the tools of qualitative research (in-depth interviews) in the context of a developing economy (India), it was found that the stronger the institutions, the more efficient is the regulation of the processes of formation of smart cities. Moreover, the leading role is played by the institutions of public administration (support for startups, creation of entrepreneurial incubators, etc.). The influence of the institute of higher education turned out to be controversial and highly dependent on the status of the university. Thus, elite universities in India (mainly in the capital) offer many programs that contribute to the development of entrepreneurship and innovation. However, less-rated institutions do not prepare graduates for work in innovative industries at all, which creates a vacuum for specialists who are ready to fulfill the tasks of a smart city.

Despite the fact that the majority of publications emphasize the importance of transitioning urban spaces to "smart rails", recently more and more works have appeared that draw attention to the potential negative consequences of such processes. Thus, researchers from Hong Kong [11] P. Lam and R. Ma in the framework of the work carried out in 2018 identified four main dangers of introducing technologies into the functioning of cities - problems of information security, leakage of personal data, incompatibility of digital information blocks and digital inequality. Without the adoption of specially designed measures, all these problems can cause the worsening of social inequality and the severance of social ties.

The analysis in [12] is based on the risks to society with the penetration of technology in all aspects of social life. It is noted that many initiatives for the formation of smart cities come down to solutionism, when the creation of different projects becomes an end in itself. The fears of scientists are confirmed by a number of empirical studies [13], studying the cases of individual cities. An analysis of the results of published studies showed that various stages of the formation of smart cities can be distinguished.

\section{METHODS}

The object of the study is the formation processes of smart cities, the effectiveness of the socio-economic systems of which is ensured by the introduction of advanced digital technologies. The research method is a logical system analysis of previous studies with the identification of the stages of the formation of smart cities. The research algorithm was as follows: we analyzed a set of studies on the development of smart cities, identified the successive stages of the formation of urban households in a digital economy, identified the stages of development of smart cities. 


\section{RESULTS}

As a result of the study, the following results were obtained on the identification of the stages of the formation of smart cities (Table 1).

Table 1 Stages of the formation of smart cities (7I-model)

\begin{tabular}{|c|c|}
\hline Stage & Description \\
\hline $\begin{array}{l}\text { 1. Formation of urban engineering } \\
\text { infrastructure (Infrastructure) }\end{array}$ & $\begin{array}{l}\text { Urban infrastructure (utilities, roads, transportation) are the basis for the } \\
\text { development of smart cities. }\end{array}$ \\
\hline $\begin{array}{l}\text { 2. Institutional support for the } \\
\text { development of the city } \\
\text { (Institutions) }\end{array}$ & $\begin{array}{l}\text { The development of a smart city is associated with formal institutions } \\
\text { embodied in the form of strategies, projects, programs of a smart city, as well } \\
\text { as informal institutions in the form of a cultural component. }\end{array}$ \\
\hline $\begin{array}{l}\text { 3. Communication systems } \\
\text { (Intranet) }\end{array}$ & $\begin{array}{l}\text { This level directly indicates the ability to support innovative infrastructure and } \\
\text { telecommunications to bring people and technical devices together to provide } \\
\text { high-speed network access throughout the city. }\end{array}$ \\
\hline $\begin{array}{l}\text { 4. Data Integration on Common } \\
\text { Digital Platforms (Integration) }\end{array}$ & $\begin{array}{l}\text { Real-time data availability is an integral part of smart cities that connect the } \\
\text { physical world with the information world and is a hallmark that justifies the } \\
\text { term "rationality". A key success factor for smart environments is the } \\
\text { provision of an open and distributed storage of information for all systems } \\
\text { implemented on different technology platforms. Smart city platforms visualize } \\
\text { urban space, collect data and implement smart applications. }\end{array}$ \\
\hline $\begin{array}{l}\text { 5. Tools for user interaction and } \\
\text { technical systems (Interfaces) }\end{array}$ & $\begin{array}{l}\text { At the interface level, web solutions are implemented that provide intelligent } \\
\text { capabilities and optimize the use of resources when processing data streams in } \\
\text { real time. }\end{array}$ \\
\hline $\begin{array}{l}\text { 6. Innovation development } \\
\text { (Innovations) }\end{array}$ & $\begin{array}{l}\text { Smart cities create a favorable innovative environment for new opportunities. } \\
\text { For this, firstly, it is necessary to change the quality and effectiveness of state } \\
\text { structures. Secondly, a smart city should be an attractive place to do business. }\end{array}$ \\
\hline $\begin{array}{l}\text { 7. The use of innovation in various } \\
\text { areas of the smart city } \\
\text { (Implementation) }\end{array}$ & $\begin{array}{l}\text { Modern theories of urbanization pay considerable attention to environmental } \\
\text { issues and environmental protection, transport, energy, as well as social issues } \\
\text { such as education, healthcare. }\end{array}$ \\
\hline
\end{tabular}

Thus, seven consecutive levels (priorities) in the development of smart cities are highlighted: engineering infrastructure (Infrastructure), institutes (Institutions), communication systems (Intranet), data integration (Integration), user and technical systems (Interfaces), innovation (Innovations), the application of innovation in the components of a smart city (Implementation).

A study of the experience of developing smart cities shows that cities need to actively interact with public and private organizations, as well as with knowledge institutions. Cities should base their smart development models on three main areas, including infrastructure, human capital, and data.

In the process of forming smart cities, leaders in this area faced problems such as providing the necessary infrastructure, creating networks of cooperation, and developing initiatives. During the implementation of smart city projects, both the public and private sectors benefit greatly from this initiative in the context of improving public services, creating innovations, developing business, and building cooperative ties. The main components of the smart city strategy are the creation of residential laboratories, electronic services, infrastructure, open data. Civil society is an integral part of the development strategy of smart cities, which requires improving communication channels between citizens and decision-makers, as well as creating conditions for the transparency of decision-making procedures and developing the capabilities of modern digital devices. The use of achievements in the field of 
artificial intelligence in the management of modern cities, the processing of large amounts of data and cognitive algorithms contribute to increasing the efficiency of urban space management. Similar tools to improve efficiency are also used in other areas of the development of smart cities, such as transport, education, and healthcare. For example, modern transport systems use large volumes of unstructured data processed in real time in their work, ensuring the functioning of transport in large cities, which is a typical example for smart urban projects. Using the tools of the digital economy, in particular big data, allows to increase the prognostic abilities of the decision-making system, to extract and analyze data that are not explicitly related to each other. Thus, it can be stated that the development of computational intelligence will make a significant contribution to the processes of socio-economic development [14].

\section{DISCUSSION}

In general, it can be noted that modeling the development of smart cities should take into account a number of features and limitations that cities face, socio-economic, technological, demographic, geographical conditions that are characteristic of them. The methodological apparatus should include both quantitative and qualitative indicators of development, take into account the institutional features, costs and benefits of the results.

The novelty of the results lies in the identification and systematization of the main levels of a smart city as part of the process of modeling the urban environment and the development of model 7I. The theoretical significance of the study lies in structuring the levels of formation of a smart city. The practical significance lies in the formation of approaches to the modeling of smart cities, including in Russian conditions. This study is the basis for further study of the development of smart cities and within the framework of the historical approach, in particular when analyzing the dynamics of the transition from a technocratic to a sociological and humanistic understanding of this phenomenon.

The phased implementation of digital technologies in socioeconomic activities helps to increase competitiveness, reduce costs and optimize management processes, and activate innovative processes. The experience of developed countries shows that the digitalization of the urban environment, the development of smart cities based on the proposed author's 7I model are based on the use of advanced digital technologies and their applications: big data processing, the use of cloud technologies, digital platforms, blockchain technology, as well as sharing economy, crowdsourcing procedures and crowdworking, the Internet of things, and other innovations. The stages of development of smart cities can be illustrated by examples of urban households in Tokyo, London, Copenhagen, Barcelona, Singapore.

In general, studying the issues of digitalization of the urban environment in leading cities such as Barcelona, Singapore, London, Copenhagen, Stockholm, Moscow, we can conclude that the processes of digitalization of these cities began with the creation of the basic infrastructure, digitalization of the transport system, and the creation of interagency interaction systems. Similar processes can now be observed on the example of Yekaterinburg. As planned, the implementation of digitalization measures in Yekaterinburg will become a factor in the development and implementation of smart services, the development of centers of smart competencies, the creation of a regional brand and the formation of a digital environment.

It can be noted that the development of an urban environment based on digital technologies organically fits into the digitalization processes of the economies of the whole country and meets the interests of states in the formation of a digital society and ensures life safety in the context of the widespread dissemination of digital technologies.

\section{ACKNOWLEDGMENT}

The study was financially supported by the Grants Council of the President of the Russian Federation, project MK526.2020 .6

\section{REFERENCES}

[1] M.-L. Marsal-Llacuna, City Indicators on Social Sustainability as Standardization Technologies for Smarter (Citizen-Centered) Governance of Cities. Social Indicators Research, 2015, 128(3), 1193-1216. doi:10.1007/s11205-015-1075-6

[2] M. Jadoul Smart practices for building smart cities. Elektrotechnik und Informationstechnik, 2016, 133(7), 341-344.

[3] P. Ingwersen, A.E. Serrano-López, Smart city research 1990-2016. Scientometrics, 2018, 117(2), 1205-1236.

[4] T. Bakıc1, E. Almirall \& J. Wareham, A Smart City Initiative: the Case of Barcelona. Journal of the Knowledge Economy, 2012, 4(2), 135-148. doi:10.1007/s13132-012-0084-9

[5] E. TekinBilbil, The Operationalizing Aspects of Smart Cities: the Case of Turkey's Smart Strategies. Journal of the Knowledge Economy, 2017, 8(3), 10321048 .

[6] S. Oueida, M. Aloqaily \& S. Ionescu, A smart healthcare reward model for resource allocation in smart city. Multimedia Tools and Applications, 2019, 78, 24573-24594 doi:10.1007/s11042-018-6647-4

[7] E. Al Nuaimi, H. Al Neyadi, N. Mohamed \& J. AlJaroodi, Applications of big data to smart cities. Journal 
[11] P. T. I. Lam, R. Ma, Potential pitfalls in the development of smart cities and mitigation measures: An exploratory study. Cities, 2018, 91, pp. 1-11. DOI: 10.1016/j.cities.2018.11.014

[8] G. Yadav, S. K. Mangla, S. Luthra, D. P. Rai, Developing a sustainable smart city framework for developing economies: an Indian context. Sustainable Cities and Society, 2019, 47, 1-14. DOI:

10.1016/j.scs.2019.101462

[9] G. F. Camboim, P. A. Zawislak, N. A. Pufal Driving elements to make cities smarter: Evidences from European projects. Technological Forecasting and Social Change, 2018, 142(C), 154-167. DOI: 10.1016/j.techfore.2018.09.014

[10] R. K. R. Kummitha, N. Crutzen, Smart cities and the citizen-driven internet of things: A qualitative inquiry into an emerging smart city. Technological Forecasting and Social Change, 2019, 140, 44-53. DOI:10.1016/j.techfore.2018.12.001
[12] S. Graham, Bridging Urban Digital Divides? Urban Polarisation and Information and Communications Technologies (ICTs). Urban Studies, 2002, 39(1), pp. 33-56.

DOI:10.1080/00420980220099050

[13] L. Anthopoulos, Smart utopia VS smart reality: Learning by experience from 10 smart city cases. Cities, 2017, 63, pp. 128-148. DOI:10.1016/j.cities.2016.10.005

[14] F. A. D'Asaro, M. A. Di Gangi, V. Perticone, \& M. E. Tabacchi, Computational Intelligence and Citizen Communication in the Smart City. InformatikSpektrum, 40(1), pp. 25-34. doi:10.1007/s00287-016$1007-0$ 